\title{
The Effect of Training Program for Staff Members to Develop Their Skills of Using Virtual Classrooms at King Saud University*
}

\author{
Khaled Nahes Alotaibi, Sultan Almutairy \\ King Saud University, Riyadh, Saudi Arabia
}

\begin{abstract}
The present study aims at showing the effectiveness of a suggested training program for staff members at Teachers' College of King Saud University to develop their skills of using virtual classrooms. The research is empirical as it used two experimental groups. The first group is taught how to use the common teaching method and the second group is taught how to use the suggested program which is based on role-playing and collaborative learning. The present research has four hypotheses that are as follows: (1) There are statistically significant differences in the skill performance of both experimental groups in favor of the group that uses the suggested program due to the main effect of the training methods followed; (2) There is a relationship between the individual skill performance of the trainees in the experimental groups and their level of cooperation with their colleagues in the work groups; (3) There is a connection between the mean of the skill performance of the work group members and the performance level of the group as a whole in the skill of giving lessons in virtual classrooms; and (4) There are no statistically significant differences in the skill performance of work groups related to academic specialty.
\end{abstract}

Keywords: virtual classrooms, e-learning, collaborative learning

\section{Introduction}

Education has achieved a breakthrough as a result of the introduction of information technology and communication into this field. This has helped educators to overcome some obstacles and increase the effectiveness of education as a whole. In fact, the interest in e-learning reflects educators' need for offering good and effective learning that goes beyond time and place. Thus, e-learning is interested in the use of synchronous and asynchronous means of communication in education.

Virtual classrooms are the most remarkable application of using synchronous means of communication in e-learning. They depend on simulating the functions of traditional classrooms by means of the Internet which keeps students connecting with the same educational environment, while they are in different locations. In fact, students who cannot attend a virtual class can watch it recorded.

The interest in using virtual classrooms in education is due to their ability to create a synchronous

\footnotetext{
*Acknowledgement: The authors extend their appreciation to the Deanship of Scientific research at King Saud University for funding the work through the research group project No. RGP-VPP-084.

Khaled Nahes Alotaibi, associate professor, Education and Psychology Department, King Saud University.

Sultan Almutairy, assistant professor, Education and Psychology Department, King Saud University.
} 
environment of individual and group interaction between students and teachers and between students among themselves. One of the advantages of the use of virtual classrooms in education as suggested by Posey et al. (2010) is that they help teachers organize their work in terms of course files, assignments, class work and some other things related to class management. Moreover, putting learning resources on the Internet allows teachers to review and update them quickly and constantly. Besides, virtual classrooms add a new dimension to learning environments that transcend time and space constraints, while imposing on teachers a new way of learning that takes learning interaction in these new environments into account (Posey et al., 2010, p. 4).

There is another advantage of virtual classrooms related to intellectual engagement of learners and the roles they play which are different from those of their traditional environments. Studies indicate that the use of virtual classrooms in education has increased social communication skills among learners and has broken their isolation through their communication with their classmates who have similar circumstances (Husu, 2000). Virtual classrooms also allow for individual contact which traditional classrooms cannot provide (Jadhav, 2006, p. 12).

The most important advantages of using virtual classrooms for teachers are the reduction in the effort made in doing paper work and the reusability which allows teachers to use learning resources to achieve many aims in more than one educational contexts (Husu, 2000). King Saud University integrated higher education into e-learning so that students at different colleges are provided with the advantages of face-to-face learning and the capabilities of synchronous and asynchronous learning at the same time. Because King Saud University believes in the necessity of activating, developing, and following up this kind of learning, it has assigned the Deanship of E-learning and Distance Learning at the university to the task of supervising e-learning systems and training both teachers and students to use them. The Learning Management System "Blackboard" is currently used by King Saud University, and the Virtual Classroom System "Illuminate Live" is also used by King Saud University, because it supports the use of the Arabic language and conforms to Blackboard. The Deanship of E-learning and Distance Learning has trained about 1,008 teachers to use these two systems in the past two years. Despite the fact is that training programs on the use of virtual classrooms in e-learning form about 20\% of the workshops offered by the Deanship of E-learning and Distance Learning, the researchers and periodic follow-up reports on teachers' use of e-learning tools found that virtual classrooms are the least e-learning tools used by teachers. Although teachers are able to use the tools of virtual learning at the end of training courses, they obviously do not use them in actual teaching situations. The researchers thought that if staff members were given an opportunity to play the role as virtual classroom teachers with their training colleagues and if trainings were given to them cooperatively to exchange experience with colleagues and gain skills from each other while teaching, their teaching performance in virtual classrooms would be better and they would use them more often. Based on what has been previously stated, the researchers suggested a developed training program on the use of lectures along with a practical demonstration and individual training in the use of virtual classroom tools followed by dividing staff members into collaborative training groups to form a virtual classroom and prepare a lesson in which they play the role of university teachers. Staff members also assess each other's performance within these small work groups. Finally, trainees are evaluated not only in 
terms of their mastery of the use of virtual classroom tools, but also in terms of using them in real teaching situations.

\section{Problem of the Research}

From the above, it can be said that many factors led to the formulation of the problem of the research. These are as follows:

(1) Staff members do not use virtual classrooms in teaching although they know how to use them;

(2) Current training programs only train teachers to use virtual classroom tools without touching on teaching skills through them;

(3) Current training programs depend on individual performance although virtual classrooms depend on collective interaction;

(4) Current training programs do not give staff members the opportunity to exchange experience with each other, or their evaluation of each other improves each other's performance;

(5) Teachers need to play a role simulating that which they do while training in the use of virtual classrooms;

(6) There is a need to clarify the specialties that can make use of virtual classrooms in higher education more than others.

The present study aims at answering the following research question: How effective is the suggested training program in providing staff members at King Saud University with skills to use virtual classrooms in teaching?

There are also other questions stemming from the previous question that the present study aims at answering, which are as follows:

(1) What is the effect of applying the suggested program to staff members' acquisition of teaching skills through using virtual classrooms?

(2) What are the differences in skill performance levels between the experimental group that was taught to use the suggested program and the group that was taught to use the current program?

(3) What is the relationship between the level of the trainees' cooperation in the work group and their mastery of teaching skills by using virtual classrooms?

(4) What is the relationship between the mean of the performance of the members of cooperative work groups in the observation card and the performance of the work group as a whole in using virtual classrooms in teaching?

\section{Aim of the Study}

The present study aims at showing the effectiveness of a suggested training program for staff members at Teachers' College of King Saud University to develop their skills of using virtual classrooms.

To achieve this aim, the present research seeks to prove that:

(1) There are statistically significant differences in the mean of both groups in skill performance in favor of the group that uses the suggested program; 
(2) There is a relationship between the suggested training program and the level of collective performance of the work group;

(3) There is a statistical connection between the level of the trainees' collaboration in the work groups and their acquisition of teaching skills in virtual classrooms;

(4) There is a relationship between specialty and the level of staff members' skill performance.

\section{Literature Review}

With the development of communication technology and the extensive use of the Internet both geographically and qualitatively, the interest in employing communication means in education has also been increased and extended to virtual classrooms, because they are an interactive e-learning environment that allows the elements of the educational process to perform the same roles that they perform in traditional learning settings but on the Internet.

There are many definitions for virtual classrooms, but they all revolve around two elements. The first one is that they are an educational means of synchronous communication, and the second one has to do with the nature of activities practiced through them that are similar to what teachers and students do in actual classrooms. For example, Griffin, Parrish, and Reigh (2006), and Jadhav (2006) considered virtual classrooms to be a learning environment depending on networks that allow both teachers and students to perform roles that are similar to the roles in traditional learning environments at a distance via synchronous communication means provided by these classrooms. Although this environment depends on synchronous communication means, it provides asynchronous communication means as well (Jadhav, 2006, p. 10; Griffin, Parrish, \& Reigh, 2006).

There have been many studies on the effectiveness of virtual classrooms and their roles in education. For example, Bodie (2009) carried out an empirical study on the extent of teachers' interaction with students in the educational process and the extent of teachers' and students' interaction with communication means in virtual classrooms which affect the participants' concepts and attitudes in the educational process and positively affect students' results at the university. The study focused on two elements which are teachers' behaviors and the communication means used to students. The study presumed that the basic dimension in this process is the teacher's verbal and non-verbal behaviors which affect the educational process more than the second dimension which includes the educational tools. The study sampled 500 students who enrolled in the psychology course and a group of teachers who are divided into two classes. Traditional teaching was used to the first class, while the virtual classroom technology was used to the other class. Each class was divided into two groups: Group 1 included 145 students, Group 2 included 154 students, Group 3 included 135 students, and Group 4 included 142 students. All of them were given a 15-minute test before the course. The study used many tools to collect data such as a questionnaire, interviews and an effect-measuring test. The results emphasized the importance of teachers' interactive behaviors in bringing students' opinions and psychology closer to the acceptance of virtual classrooms in comparison with traditional classrooms and overcoming the problem of teachers' low voice sometimes. Besides, the results of the study found that there is a high level of interaction and connection 
between teacher's behaviors and virtual classrooms which contributed to teachers' satisfaction reflected in their attitudes to virtual classrooms ( Bodie, 2009).

On the other hand, Yuzer's (2007) study at the University of Anatolia in Turkey aimed at discussing "the mechanism of visual communication” through direct online communications in the virtual classroom applications and the discussion of the technological infrastructure of verbal visual communication. The study was applied to a group of schools in using the online virtual classroom technologically. The sample included a group of middle and high school students who were given a questionnaire to collect and analyze data. The study came to the conclusion that the use of online virtual classrooms as a technological method to teach proved to be important and effective in the educational process. In fact, virtual classrooms include a number of tools provided by technology according to teaching and learning theories in synchronous virtual classrooms following an organized course of action. All educational methods and tools in relation to virtual classrooms are used online (Yuzer, 2007). Another study prepared by Yuzer in collaboration with Ayden (Ayden \& Yuzer, 2006) in 2006 aimed at evaluating synchronous virtual classrooms, which train teachers to teach English at a distance in Turkey. The study was prepared as a guide project to teach the second-year students in an advanced reading course over two years. The study sample included about 1,000 university students who attended the program, and it represented all university stages for two years and used a questionnaire to collect data. The study examined all students' responses about the importance and the effectiveness of virtual classrooms in this program. The study came to the conclusion that virtual classrooms help to promote self-confidence and encourage students to learn independently, compared with traditional classrooms. Besides, the study emphasized the continuity of students' learning and ability to understand virtual classrooms and had positive attitudes towards them (Ayden \& Yuzer, 2006).

Rich, Cowan, Herring, and Wilkes (2009) evaluated the use of virtual classrooms at the University of Athens in the state of Alabama from the point of view of students and teachers, in order to learn about the strengths and the weaknesses of applying synchronous virtual classrooms through a questionnaire designed for this purpose. The study arrived at the conclusion that there were a number of obstacles for the effective application of virtual classrooms, such as the inability of students to communicate with their classmates and teachers at the beginning, and the uncomfortable feelings of about $50 \%$ of the students towards using these classrooms, because they are not suitable for what is applied in traditional classrooms. As college teachers succeeded in acquiring application skills and as virtual classrooms were activated in educational practices, the study reflected an improvement in learning outcomes as a result of applying synchronous virtual classrooms to education online represented in lectures, discussions, electronic boards, and electronic educational tools.

Parker (2006) made a study that aimed at identifying the features, skills, and techniques that teachers had to run in virtual classrooms at the Community College in San Francisco in the state of California in the United Sates of America. It also aimed at educating staff members on how to make use of virtual classroom management. The sample included 47 teachers with an interview and a questionnaire based on theoretical analysis as its tools. Twenty-six questions were given to the sample subjects including the academic 
qualifications, training, concept of developmental education, features, techniques, and skills which help in traditional classrooms as well as virtual classrooms, and the most important challenges facing them, as they moved from traditional classrooms to virtual classrooms. The study came to the conclusion that there were a number of features, skills, and techniques that helped teachers move from traditional classrooms to virtual classrooms.

There have been many strategies of training in technological skills, such as cooperative learning. In fact, Clark and Mayer (2008) defined computer-assisted cooperative learning as a cooperative connection between group members consisting of two to five people using synchronous and asynchronous communication tools to support learning aims. In another definition, they regarded computer-assisted cooperative learning as "An educational program through which a group of two to five people can work together on an educational task using digital technology” (Clark \& Mayer, 2008, p. 429). Jianhua and Akahori (2001, p. 3) saw that online cooperative learning is similar to the environment of traditional classrooms and consists of five components which are peers, work groups, tutor, communication, and an online learning environment. In addition, Srinivas (2010, p. 1) mentioned many advantages of using cooperative learning, such it teaches practical skills and self-management skills and makes the acquisition of skills more effective inside and outside classrooms, not to mention the experience that teachers could only gain from their colleagues.

A study carried out by D. Johnson, R. Johnson, and Holubec (1994, p. 6) suggested that the concept of cooperative learning is a new approach to education in which students work in small groups to achieve common aims. Students were divided into small groups of two to five students, in which students worked with each other to do the work successfully after they received instructions from their teacher. According to D. Johnson, R. Johnson, and Holubec's (1994) strategy, cooperative work, unlike competitive and individual work, increases students' performance and achievement, reinforces positive relationships and promotes psychological well-being and self-esteem.

Not only has collaborative learning been proved to be effective in training and learning, but there is also another strategy used extensively in training. This is role playing. In fact, role playing has many advantages for teaching and training because it excites students' interest in a learning or training topic through mixing learning activities with role playing in classrooms to maximize benefits from course contents and increase students' positive participation in different tasks as their roles differ according to tasks. Besides, role playing provides students with safe solutions and opportunities to practice skills that motivate students to learn and promotes creative critical thinking, social and personal attitudes, values and skills (Poorman, 2002, p. 200). A study made by Kerr, Troth, and Pickering (2003) emphasized the importance of using role playing in providing university students with an understanding of information systems and a solution to deal with them. The suggested training of the present study depends on integrating role playing into cooperative learning, as strategies aim at providing teachers with teaching skills through virtual classrooms.

\section{Research Method and Procedures}

The present research is empirical as it studies the effectiveness of a suggested program as an independent 
variable for staff members' acquisition of teaching skills in using virtual classrooms as a dependent variable. The research was applied to 43 staff members at King Saud University who were divided into two groups. The first group included 20 trainees who studied to use the current way of training that depends on the demonstration of skills and personal practice. The other group included 23 staff members who studied in a developed way by integrating role playing into collaborative learning according to the training strategy followed to overcome some of the problems that were stated in the problem of the research.

\section{Research Tools}

An observation card was designed to evaluate the skills of trainees' practical performance in virtual classrooms. The card consisted of 10 fields, each of which represented one of the skills of using virtual classrooms in the Elluminate System. The maximum end of the card was 100 points. The validity of the card was calculated by giving it to 10 referees from staff members who specialized in it, while the consistency was calculated by means of the retest method used for a survey sample of 10 trainees who had previously used virtual classrooms. Consistency was calculated by Cronbach's Alpha which was 0.83 that was good for tool consistency. A peer evaluation card was also designed in the work groups. It is a specialty card for each trainee to evaluate his/her peers in the training group and allows each trainee to evaluate his/her peers at five levels based on the peers' participation and cooperation in the work group. It was then judged and approved. Consistency was calculated by calculating the connection between peers' grades of the same tests, and it was 0.82. The researchers designed an evaluation card for all the training groups through a group presentation in which each training group evaluates the other four training groups according to six skills related to group performance. Its validity was calculated by two referees, and its consistency was calculated by using the retest method. Cronbach's Alpha was 0.80 and it was good for card consistency. The present study began reviewing the training program that was carried out at the Saudi universities on the skills of using virtual classrooms in teaching, as well as some international examples. The researchers set the program as follows.

\section{Description of the Training Program}

The training program consists of 16 training hours over four days including eight sessions, each of which lasts two hours. On the first day, there was a theoretical lecture followed by a presentation of some skills of using virtual classrooms. In the second session of that day, the trainees were given the opportunity to practice the skills related to setting a virtual classroom individually. Besides, the trainees were asked to divide themselves into collaborative learning groups during the rest of the training period. They were divided into five training groups, each of which included four to five trainees. On the second day, trainees were trained to prepare a lesson by using virtual classrooms and make PowerPoint presentations. Each training group chose one member to play the role of the teacher and set a virtual classroom, into which they signed as students, so that he/she would carry out the skills in place of training. Then they exchanged roles in the two training sessions. They were also asked to prepare a lesson idea collectively through a virtual classroom and set collaboratively and record what they did. The presentation of projects would take place on the last day of the 
training course. On the third day, they were trained on the skills of preparing virtual classroom tests, and the strategy of role playing was also used. At the end of the training day, each group was asked to add an interactive test to the group lesson that they had prepared collectively. On the fourth training day, trainees were led to present their projects. Each training group made its presentation for 20 minutes, and the rest of the groups were asked to evaluate the group's presentation in general through an evaluation card designed for this purpose. At the end of the group presentations, each group was asked to evaluate its members' performance, according to how cooperative they had been at every stage of the project. A peer evaluation card was designed by the researchers to evaluate peers' performance in the work group. At the last stage of the training day, each trainee practiced what he/she had learned under the supervision of a training body and their performance was evaluated through the observation card prepared by the research for this purpose. As for the experimental group which studied in the traditional way, it lasted for four training days and for the same training period, but the training activities were carried out individually when each trainee set a virtual classroom, prepared a lesson, made his/her presentation which was later evaluated by the trainer. The observation card was applied to the trainees whose skill performances were calculated.

\section{Research Findings}

Through applying the observation card of trainees' practical performance and calculating the application results and comparing the trainees' grades in the first experimental group which studied according to the suggested program and in the second experimental group which studied in the traditional way all by cards and skills, the following results were found in Table 1.

Table 1

Results of Test T for the Differences Between Both Experimental Groups

\begin{tabular}{|c|c|c|c|c|c|c|}
\hline Skill & Group & Number & Mean & DS & $T$ value & Significance value \\
\hline \multirow{2}{*}{ First } & First & 23 & 8.91 & 1.23 & 3.522 & \multirow{2}{*}{ Significant at 0.01} \\
\hline & Second & 20 & 7.70 & 0.978 & & \\
\hline \multirow{2}{*}{ Second } & First & 23 & 8.82 & 1.26 & 3.769 & \multirow{2}{*}{ Significant at 0.01} \\
\hline & Second & 20 & 7.50 & 1.00 & & \\
\hline \multirow{2}{*}{ Third } & First & 23 & 8.73 & 1.13 & 3.474 & \multirow{2}{*}{ Significant at 0.01} \\
\hline & Second & 20 & 7.55 & 1.09 & & \\
\hline \multirow{2}{*}{ Fourth } & First & 23 & 9.08 & 0.945 & 5.505 & \multirow{2}{*}{ Significant at 0.01} \\
\hline & Second & 20 & 7.45 & 0.998 & & \\
\hline \multirow{2}{*}{ Fifth } & First & 23 & 9.00 & 1.12 & 4.953 & \multirow{2}{*}{ Significant at 0.01} \\
\hline & Second & 20 & 7.45 & 0.887 & & \\
\hline \multirow{2}{*}{ Sixth } & First & 23 & 9.00 & 1.00 & 4.440 & \multirow{2}{*}{ Significant at 0.01} \\
\hline & Second & 20 & 7.65 & 0.988 & & \\
\hline \multirow{2}{*}{ Seventh } & First & 23 & 8.86 & 0.967 & 3.744 & \multirow{2}{*}{ Significant at 0.01} \\
\hline & Second & 20 & 7.70 & 1.08 & & \\
\hline \multirow{2}{*}{ Eighth } & First & 23 & 9.21 & 0.735 & 6.689 & \multirow{2}{*}{ Significant at 0.01} \\
\hline & Second & 20 & 7.50 & 0.945 & & \\
\hline \multirow{2}{*}{ Ninth } & First & 23 & 9.04 & 5.056 & 0.928 & \multirow{2}{*}{ Significant at 0.01} \\
\hline & Second & 20 & 7.60 & & 0.940 & \\
\hline \multirow{2}{*}{ Tenth } & First & 23 & 9.30 & 8.118 & 0.875 & \multirow{2}{*}{ Significant at 0.01} \\
\hline & Second & 20 & 7.35 & & 0.670 & \\
\hline \multirow{2}{*}{ Total } & First & 23 & 90.00 & 5.865 & 8.42 & \multirow{2}{*}{ Significant at 0.01} \\
\hline & Second & 20 & 75.45 & & 7.72 & \\
\hline
\end{tabular}


It is clear from Table 1 that there are statistically significant differences at 0.01 and they are all in favor of the first experimental group which studied to use the suggested program. These differences cover the ten skills and the total as well. This means that the use of the suggested program increased skill performance which leads to the acceptance of the first hypothesis of the research which claimed that, "There are statistically significant differences in skill performance between both experimental groups in favor of the group that uses the suggested program due to the main effect of the training methods used”.

Table 2

The Results of the Calculation of the Connection Coefficient Between Trainees' Skill Performance in the Work Group and the Degree of Their Cooperation in the Work Groups According to the Mean of Peer Evaluation

\begin{tabular}{ll}
\hline Connection coefficient & Connection estimate method \\
\hline Spearman & 0.784 \\
Pearson & 0.782 \\
\hline
\end{tabular}

Table 2 shows that these are strong connection coefficients that lead to the acceptance of the second hypothesis which stated that, "There are a statistic connection between the trainees' individual skill performance in the experimental group and cooperation level with their colleagues in the work groups".

Table 3

The Results of Calculating the Connection Coefficient Between the Mean of Skill Performance of the Training Group Members and Their Collective Performance

\begin{tabular}{ll}
\hline Connection coefficient & Connection estimate method \\
\hline Spearman & 0.753 \\
Pearson & 0.750 \\
\hline
\end{tabular}

Table 3 shows that there are strong connection coefficients which lead to the acceptance of the third hypothesis which stated that, "There are a statistical connection between the mean of skill performance of the group members in the work groups and the overall performance of the groups in the skill of giving lessons via virtual classrooms".

As for the fourth and fifth hypotheses which investigated the relationship between specialty and skill performance of the group members, the members in the first experimental group were divided into work groups according to specialty followed by calculating the analysis of one-dimensional difference between them. The results were as follows in Table 4.

It is clear from Table 4 that there are no differences in specialty in terms of individual skills or all the skills among work groups. In other words, there are no differences among the members of the first experimental group in terms of trainees' specialty, which leads to the acceptance of the result of the fourth hypothesis of the research which stated that, "There are no statistically significant differences in the skill performance of the members of the work groups in terms of specialty". 
Table 4

Difference Analysis between Members of the first Experimental Group to Show the Effect of Skill Performance of Group Members According to Specialty

\begin{tabular}{|c|c|c|c|c|c|}
\hline Skill & Group & No. & Rank mean & K2 value & Significance level \\
\hline \multirow{5}{*}{ First } & First & 4 & 8.50 & \multirow{5}{*}{3.450} & \multirow{5}{*}{ Insignificant } \\
\hline & Second & 4 & 13.38 & & \\
\hline & Third & 5 & 13.90 & & \\
\hline & Fourth & 5 & 9.30 & & \\
\hline & Fifth & 5 & 14.50 & & \\
\hline \multirow{5}{*}{ Second } & First & 4 & 8.62 & \multirow{5}{*}{3.184} & \multirow{5}{*}{ Insignificant } \\
\hline & Second & 4 & 13.88 & & \\
\hline & Third & 5 & 14.90 & & \\
\hline & Fourth & 5 & 9.60 & & \\
\hline & Fifth & 5 & 12.70 & & \\
\hline \multirow{5}{*}{ Third } & First & 4 & 7.384 & \multirow{5}{*}{3.872} & \multirow{5}{*}{ Insignificant } \\
\hline & Second & 4 & 10.62 & & \\
\hline & Third & 5 & 14.40 & & \\
\hline & Fourth & 5 & 12.0 & & \\
\hline & Fifth & 5 & 14.40 & & \\
\hline \multirow{5}{*}{ Fourth } & First & 4 & 7.88 & \multirow{5}{*}{3.897} & \multirow{5}{*}{ Insignificant } \\
\hline & Second & 4 & 12.25 & & \\
\hline & Third & 5 & 12.40 & & \\
\hline & Fourth & 5 & 10.70 & & \\
\hline & Fifth & 5 & 16.0 & & \\
\hline \multirow{5}{*}{ Fifth } & First & 4 & 12.12 & \multirow{5}{*}{2.993} & \multirow{5}{*}{ Insignificant } \\
\hline & Second & 4 & 14.50 & & \\
\hline & Third & 5 & 11.50 & & \\
\hline & Fourth & 5 & 8.20 & & \\
\hline & Fifth & 5 & 14.20 & & \\
\hline \multirow{5}{*}{ Sixth } & First & 4 & 12.62 & \multirow{5}{*}{6.300} & \multirow{5}{*}{ Insignificant } \\
\hline & Second & 4 & 17.00 & & \\
\hline & Third & 5 & 14.60 & & \\
\hline & Fourth & 5 & 8.30 & & \\
\hline & Fifth & 5 & 8.60 & & \\
\hline & First & 4 & 11.75 & & \\
\hline & Second & 4 & 16.25 & & \\
\hline Seventh & Third & 5 & 13.40 & 3.865 & Insignificant \\
\hline & Fourth & 5 & 9.70 & & \\
\hline & Fifth & 5 & 9.70 & & \\
\hline & First & 4 & 9.62 & & \\
\hline & Second & 4 & 14.25 & & \\
\hline Eighth & Third & 5 & 15.30 & 3.567 & Insignificant \\
\hline & Fourth & 5 & 9.70 & & \\
\hline & Fifth & 5 & 11.10 & & \\
\hline & First & 4 & 10.88 & & \\
\hline & Second & 4 & 13.38 & & \\
\hline Ninth & Third & 5 & 14.50 & 1.610 & Insignificant \\
\hline & Fourth & 5 & 10.00 & & \\
\hline & Fifth & 5 & 11.30 & & \\
\hline & First & 4 & 11.00 & & \\
\hline & Second & 4 & 12.75 & & \\
\hline Tonth & Third & 5 & 15.60 & 7.469 & Insignificant \\
\hline Tenth & Fourth & 5 & 6.00 & & \\
\hline & Fifth & 5 & 14.60 & & \\
\hline & First & 4 & 10.50 & & \\
\hline & Second & 4 & 14.38 & & \\
\hline Total & Third & 5 & 14.10 & 2.862 & Insignificant \\
\hline & Fourth & 5 & 8.20 & & \\
\hline & Fifth & 5 & 13.00 & & \\
\hline
\end{tabular}




\section{Discussion of Results}

From what has been stated previously, it became clear that the use of collaborative learning and role playing in trainees to use virtual classrooms had developed trainees' individual skill performance not only in using virtual classrooms, but also in making full use of them. The researcher found a significant relationship between staff members' skills and the cooperation in work groups. It was clear that more skilled teachers were more cooperative in the work groups, while collective performance of work groups was affected by the mean of the skills of the participating teachers. There was also a significant relationship between the means of the skills of work groups and the final performance of the group. The study also came to the conclusion that there were no statistically significant differences in different specialties which practiced training on the use of virtual classrooms. In other words, specialty was not an effective factor in providing staff members with the skill of using virtual classroom in teaching. In accordance with the results of the study, the research recommends that:

(1) The actual use of virtual classrooms in university teaching is vital;

(2) There are different strategies used in training that meet the various needs of training;

(3) Trainees should be engaged in teaching in virtual classrooms through role playing;

(4) Experience should be exchanged among trainees during the training period through cooperative activities;

(5) Staff members with different specialties should be trained to use virtual classrooms in teaching and should ensure that training groups are divided according to specialty so that cooperative work becomes easy among group members and reflects on the end products of the work groups.

\section{References}

Aydin, B., \& Yuzer, T. V. (2006). Building a synchronous virtual classroom in a Distance English Language Teacher Training (DELTT) Program in Turkey. Turkish Online Journal of Distance Education, 7(1), 9-20.

Bodie, L. W. (2009). An experimental study of instructor immediacy in the Wimba virtual classroom. Retrieved from http://www. udini.proquest.com/view/an-experimental-study-of-instructor-pqid:1850827361/

Chen, C. (2008). The effectiveness of computer supported collaborative learning on helping tasks in a mathematics course. University of Southern Californi.

Clark, R. C., \& Mayer, R. E. (2009). E-learning and the science of instruction (2nd ed.). San Francisco: Pfeiffer.

Fogg, P. (2001). A history professor engages students by giving them a role in the action. Chronicle of Higher Education, 48(12), A12-13.

Griffin, R. E., Parrish, D., \& Reigh, M. (2006). Using virtual classroom tools in distance learning: Can the classroom be re-created at a distance? Retrieved from http://www.commons.internet2.edu/docs/CERMUSACollabEval.pdf

Guy P., et al. (2010). The advantages and disadvantages of the virtual classroom and the role of the teacher. In 2010 Southwest Decision Sciences Institute Conference. Retrieved from http://www.swdsi.org/swdsi2010/SW2010_Preceedings/papers/PA126.pdf

Husu, J. (2000). Access to equal opportunities: Building of a virtual classroom within two "conventional” schools. Journal of Educational Media, 25(3), 217-228.

Jadhav, S. K. (2006). Project report on virtual classroom. Retrieved from http://www.cdacmumbai.in/design/corporate_site /override/ pdf-doc/virtual-classroom.pdf

Jianhua, Z., \& Akahori, K. (2001). Web-based collaborative learning methods. Retrieved from http://www.eecs.kumamoto-u. ac.jp/ITHET01/proc/139.pdf

Johnson, D., Johnson, R., \& Holubec, E. (1994). Cooperative learning in the classroom. Alexandria, V. A.: Association for Supervision And Curriculum Development. 
Kerr, D., Troth, A., \& Pickering, A. (2003). The use of role-playing to help students understand information systems case studies. Journal of Information Systems Education, 14(2), 167-167.

Parker, C. A. (2007). Exploring the qualities, skills, attitudes and techniques among highly rated community college teachers that may foster community, connectedness and discourse in the virtual classroom: A qualitative study (Unpublished doctoral dissertation, Argosy University/San Francisco).

Poorman, P. B. (2002). Biography and role-playing: Fostering empathy in abnormal psychology. Teaching of Psychology, 29(1), 32-36.

Rich, L. L., Cowan, W., Herring, S. D., \& Wilkes, W. (2009). Collaborate, engage, and interact in online learning: Successes with wikis and synchronous virtual classrooms at Athens State University. Paper presented at the 14th Annual Instructional Technology Conference. March 30-April 1, 2009.

Srinivas, S. (2010). Collaborative learning. Retrieved from http://www.gdrc.org/kmgmt/c-learn/

Yuzer, T. V. (2007). Generating virtual eye contacts through online synchronous communications in virtual classroom application. Turkish Online Journal of Distance Education, 8(3), 43-54. 